\title{
Regulation of the kinin receptors after induction of myocardial infarction: a mini-review
}

\section{Tschöpe ${ }^{1}$, \\ S. Heringer-W alther ${ }^{2}$ and $\mathrm{T}$. W alther ${ }^{1,3}$}

\author{
${ }^{1}$ Department of Cardiology and Pneumology, University Hospital Benjamin Franklin, \\ Free U niversity of Berlin, Berlin, Germany \\ ${ }^{2}$ Laboratório de Hipertensão, Departamento de Fisiologia e Biofísica, \\ Instituto de Ciências Biológicas, Universidade Federal de Minas Gerais, \\ Belo Horizonte, MG, Brasil \\ 3M ax-D elbrück Center for M olecular Medicine, Berlin-Buch, Germany
}

\section{Correspondence \\ T. Walther \\ Department of Cardiology and \\ Pneumology \\ University Hospital Benjamin \\ Franklin \\ Hindenburgdamm 30 \\ D-12200 Berlin \\ Germany \\ Fax: +49-30-8445-3565 \\ E-mail: thowal@ mdc-berlin.de}

Presented at the III International Symposium on Vasoactive Peptides, Belo Horizonte, MG, Brasil,

O ctober 8-10, 1999.

Research supported by a grant of the Deutsche Forschungsgemeinschaft (DFG; No. TS-64/2-1).

Received February 3, 2000

Accepted February 14, 2000

\section{Abstract}

It is well known that the responses to vasoactive kinin peptides are mediated through the activation of two receptors termed bradykinin receptor B1 (B1R) and B2 (B2R). The physiologically prominent B2R subtype has certainly been the subject of more intensive efforts in structure-function studies and physiological investigations. However, the B1R activated by a class of kinin metabolites has emerged as an important subject of investigation within the study of the kallikreinkinin system (KKS). Its inducible character under stress and tissue injury is therefore a field of major interest. Although the KKS has been associated with cardiovascular regulation since its discovery at the beginning of the last century, less is known about the B1R and B2R regulation in cardiovascular diseases like hypertension, myocardial infarction (MI) and their complications. This mini-review will summarize our findings on B1R and B2R regulation after induction of MI using a rat model. We will develop the hypothesis that differences in the expression of these receptors may be associated with a dual pathway of the KKS in the complex mechanisms of myocardial remodeling.

\section{The kallikrein-kinin system}

Kinins are biologically active peptides which exert a broad spectrum of physiological effects, including vasodilation, smooth muscle contraction and pain induction. Several kinin peptides have been identified in mammalian species: the nonapeptide bradykinin (BK) and the decapeptide Lys-bradykinin (kallidin) belong to the best investigated members of the kinin family. Kinins are

\section{Key words}

- B1 receptor

- B2 receptor

- Bradykinin

- Heart infarction

- Kallikrein-kinin system formed by cleavage from precursor kininogens by kallikreins (KLK). They are rapidly degraded by several kininases, including kininase II which is identical to angiotensinconverting enzyme. Kinins exert their effect after stimulation of their cell surface receptors: $\mathrm{BK} \mathrm{B} 1$ receptor $(\mathrm{B} 1 \mathrm{R})$ and $\mathrm{B} 2$ receptor (B2R). Whereas the $\mathrm{B} 2 \mathrm{R}$ is responsive to the intact kinins, BK and kallidin, the B1R has a higher affinity for the carboxypeptidase metabolites of kinins, des-Arg'-BK and des- 
$\operatorname{Arg}^{10}$-kallidin (1).

Since circulating concentrations of kinins are usually too low to cause systemic effects and an independent cardiac kallikreinkinin system (KKS) has been discovered, autocrine and paracrine actions of kinins have received increasing scientific attention. In rat cardiac atria and ventricles glandular KLK, its mRNA (2) and low-molecularweight kininogens could be detected $(3,4)$. Coronaries also contain and release KLK (2). Binding sites for BK have been described in myocytes as well as in cardiac fibroblasts $(2,5)$. Thus, cardiac kinins may be generated continuously by a local KKS. The importance of kinins in the regulation of cardiovascular physiology was recently documented in B2R-knockout mice, which develop cardiac failure and hypertension $(6,7)$.

Under pathophysiological conditions, kinins are synthesized de novo at sites of tissue damage, where they participate in the acute inflammation response in the microvasculature and aid in tissue repair and healing (1). These include acute pro-inflammatory effects like vasodilation, pain, and vascular hyperpermeability. In addition, kinins have also growth-promoting activities, although their role in cellular proliferation in vivo remains poorly understood. They can stimulate proliferation of a number of cell types, including fibroblasts, particularly in the presence of other growth factors, like insulin or transforming growth factor- $\beta$. However, depending on the study design, weak mitogen or anti-mitogen effects of kinins have been found. It appears that activated kinin receptors may stimulate multiple proliferative pathways, like the protein kinase $\mathrm{C}$ pathway, as well as the generation of arachidonate metabolites such as prostaglandin E2 which inhibit proliferation (8). Most of these effects can be abolished using a B2R antagonist $(1,8)$.

Stimulation of the B1R can also produce a range of pro-inflammatory effects includ- ing edema, pain and promotion of bloodborne leukocyte trafficking. Studies in B1Rknockout mice with induced peritoneal inflammation suggest that the B1R may play an important role in the pathogenesis of chronic inflammation diseases (9). Similarly to the $\mathrm{B} 2 \mathrm{R}$, also the $\mathrm{B} 1 \mathrm{R}$ can mediate some of the mitogen and anti-mitogen effects of kinins. However, the involvement of the B1R axis within the KKS in cardiovascular injuries is still poorly investigated. Exogenous intra-arterial injection of des-Arg ${ }^{9}$-BK mediates hypotension and a reduction in peripheral resistance with a consecutive increase in cardiac output (10). Under septic conditions it provokes cardiovascular shock (11). Expression of B1R by cardiomyocytes under ischemic conditions has been identified by using B1R agonists and antagonists in in vitro and ex vivo models. Thus, ischemia-induced cardiac B1R stimulation was only indirectly demonstrated by the capacity to modulate positively or negatively noradrenaline release (12), by reduction of reperfusion arrhythmia (13) or by preservation of endothelium-dependent vasodilation (14). However, B1R induced by post-surgery stress could not be excluded in these studies.

\section{Classification of kinin receptors}

Kinins mediate their biological effects through the stimulation of two receptors, classified as B1R and B2R according to the relative potencies and affinities for their agonists. BK and kallidin are the natural agonists of B2R. They are, in contrast to their metabolites des-Arg ${ }^{9}$-BK and des-Arg ${ }^{10}$-kallidin, weak B1R ligands (15). B2R mediates most, if not all, of the effects usually attributed to kinins. Whereas the B2R is ubiquitously expressed in many tissues and cell lines, B1R is usually not detectable under physiological conditions and is synthesized de novo under pathological conditions such as sepsis, inflammation, or oxidative stress, possibly indicating an additional mechanism 
in tissue injury and repair within the KKS (9).

In addition to these criteria, biochemical and molecular differences have also been demonstrated and used to classify the kinin receptors into B1R and B2R subtypes: according to hydrophobicity analysis, both receptors belong to the superfamily of G-protein-coupled cell-surface receptors (G-PCR), also called seven transmembrane receptors (16). The two receptors have an overall homology of $35 \%$, and most of the homology is located in the seven transmembrane regions. The intracellular loops of both BK receptors exhibit only minor homologies, despite the fact that both types are predominantly coupled to the same $\mathrm{G} \alpha$ subunit, Gq, leading to a phospholipase C-dependent release of inositol phosphate (IP) and a transient increase in intracellular calcium $\left[\mathrm{Ca}^{2+}\right]$ upon ligand stimulation $(17,18)$. In endothelial cells the enhancement of cytosolic $\left[\mathrm{Ca}^{2+}\right]$ leads to an activation of arachidonic acid metabolism via phospholipase A2 and an increase in nitric oxide (NO) formation via the calcium-calmodulin-dependent NO-synthase. Endothelial prostaglandin and NO exert several pharmacological effects of kinins via adenosine monophosphate (cAMP) and guanosine monophosphate (cGMP) formation in vascular smooth muscle cells such as relaxation, anti-proliferation and antiischemic effects (19).

\section{Characterization of the B2R subtype}

Although both receptors induce the generation of IP, functional responses show clear differences. Studies in Chinese hamster ovary cells (CHOC) showed that B2R is a socalled recycling receptor (18). $\mathrm{B} 2 \mathrm{R}$ responds to stimulation with a short, strong signal but also immediately undergoes a rapid loss of functional responses, receptor internalization and sequestration, ligand dissociation and, upon long-term stimulation, its own mRNA and protein down-regulation (18, 20,21). The result of these processes is the creation of a strong signal that is of short duration and leads to fast signal termination.

\section{Characterization of the B1R subtype}

The B1R may be one of the most profoundly regulated G-PCR, to the point of being completely inducible by inflammatory stimuli. It can be strongly up-regulated by growth factors and cytokines like interleukin $1 \beta$ (Il-1ß), interleukin 2 (Il-2), interleukin 8 (Il-8) or bacterial lipopolysaccharides, apparently via the nuclear factor $\mathrm{\kappa B}$-like binding site located proximal to the TATA box and transcription initiation site $(22,23)$. Although the effects of B1R stimulation under inflammatory conditions are often qualitatively similar to those of BK and B2R stimulation, the way of B1R signal recognition itself shows almost the opposite behavior compared to the $\mathrm{B} 2 \mathrm{R}$ after stimulation $(17,18)$. The B1R is suggested to be a noninternalizing receptor. Its ligand stimulation does not comprise receptor internalization or sequestration and shows almost no desensitization and only a very slow ligand dissociation. Indeed, long-term stimulation of the B1R actually leads to an increased expression in CHOC. Thus, all responses of the B1R to agonist stimulation favor persistent signaling, which could represent a mechanism whereby the KKS contributes to the change of an acute to a chronic phase of inflammation and/or tissue repair.

\section{Regulation of B1R and B2R after induction of myocardial infarction}

After myocardial infarction (MI), increased plasma levels of KLK, kininogen and BK were found (24-28), and the increase in plasma KLK levels was positively correlated with the early survival rate of post-MI patients (29). It has been shown that kinins are released directly from the myocardium during MI $(27,28)$ and contribute to the impact of ischemic damage (29). Several car- 
dioprotective effects of BK have been found by various authors after induction of myocardial ischemia. In isolated working rat hearts, BK improved cardiac performance and metabolism during ischemia and reperfusion (17,30). Recent emerging concepts propose also an "anti-trophic" role for kinins in attenuating the process of cardiac and vascular remodeling (31). But which kinin receptor subtype is involved in effects under these conditions is still under investigation. B2R suffers rapid internalization and hence apparent desensitization after chronic BK stimulation as shown in in vitro and ex vivo studies devoid of tissue damage $(18,20,21)$. Thus, the myocardial effects of kinins after induction of MI could be limited by a downregulation of B2R. In addition, various experimental settings based on isolated rat cardiac tissue have been used to document indirectly ischemia-induced B1R up-regulation $(12,13)$. But, whether the post-isolation itself or the MI leads to the B1R up-regulation in this approach has not been tested rigorously.

To clarify this question we performed studies in a rat model of MI in vivo. We examined the regulation of the myocardial $\mathrm{B} 1 \mathrm{R}$ and $\mathrm{B} 2 \mathrm{R}$ expression with a specific RNase protection assays (RPA) at the exudative $(6 \mathrm{~h}$ post-MI), inflammatory $(24 \mathrm{~h}$ post-MI) or early fibrogenic phase (6 days post-MI) of wound healing after ischemiainduced tissue damage. These results were compared to those obtained for time-matched sham-operated rats.

Figure 1 - Time curve for the expression of the kinin receptors $\mathrm{B} 1$ (B1R) and B2 (B2R) in the left ventricle $6 \mathrm{~h}, 24 \mathrm{~h}, 48 \mathrm{~h}$ and 6 days after induction of myocardial infarction (MI). In both cases, the number for the highest expression was taken as $100 \%$.

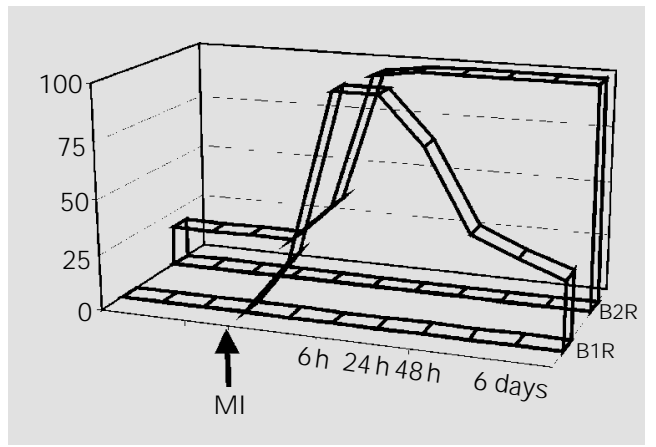

\section{Regulation of the B2R after induction of MI}

In agreement with others, we found a basal B2R expression in the left ventricle $(\mathrm{LV})$ as well as in the right ventricle (RV) of the heart in non-operated rats $(32,33)$. No regulation of $\mathrm{B} 2 \mathrm{R}$ expression has been found in time-matched sham-operated rats, indicating that the operation itself did not induce any $\mathrm{B} 2 \mathrm{R}$ regulation (33).

Surprisingly, we found an up-regulation of B2R expression starting as early as $6 \mathrm{~h}$ after MI induction with a peak at $24 \mathrm{~h}$ which was maintained in the LV for at least 6 days $(33,34)$ (Figure 1). This up-regulation also correlated with an increase in the protein level of the B2R in the scar of the LV at least 6 days after MI induction, further indicating a role of the B2R during the early stages of tissue repair after MI (33).

Furthermore, an increase in B2R up-regulation was also found in the RV, as well as in the interventricular septum, which are remote from infarct site (33).

\section{Regulation of the B1R after induction of MI}

In contrast to Marceau et al. (32), who found a basal myocardial B1R mRNA expression in the rabbit using a non-quantitative duplex reverse transcription PCR (RTPCR), we detected no B1R expression in the hearts of non-operated or time-matched sham-operated rats using $25 \mu \mathrm{g}$ RNA for a specific rat B1R RPA (Figure 1). Six hours after coronary ligation, B1R expression was first detected (35). Similar to the B2R, the up-regulation of B1R expression reached its maximum $24 \mathrm{~h}$ after induction of MI. However, 6 days after MI induction B1R expression was significantly reduced to a level comparable to that measured $6 \mathrm{~h}$ after coronary occlusion (Figure 1). In contrast to the $\mathrm{B} 2 \mathrm{R}$ expression in the RV no B1R expression could be detected after induction of MI 
at any time, whereas no data are available for the septum.

\section{Physiological relevance of B1R and B2R up-regulation after MI induction}

Myocardial ischemia is accompanied by an enormous release of cardiac BK, which can be maintained for several weeks (29). Thus, according to its behavior described in cell lines after chronic stimulation, we expected a down-regulation of the $\mathrm{B} 2 \mathrm{R}$ in this situation. In contrast, B1R expression should be stimulated since the post-MI is also an inflammatory process. However, we have clearly shown that both BK receptor subtypes are up-regulated after induction of MI. Thus, the regulation of the $\mathrm{B} 2 \mathrm{R}$ differs compared to results of studies designed under non-physiological or basal conditions, whereas the finding of the up-regulation of the B1R after myocardial ischemia expands the knowledge of the stimuli involved in its induction. However, the expression pattern of the two BK receptors differs with respect to their time curve (Figure 1) and their location, which may indicate a dual mechanism of the KKS after induction of MI.

\section{Time-dependent differences in the regulation of bradykinin receptors after induction of myocardial infarction}

The up-regulation of both BK receptors 6 to $24 \mathrm{~h}$ after induction of $\mathrm{MI}$ indicates their role in the early exudative phase of wound healing. The mechanism for this up-regulation still has to be investigated. However, cytokines, like Il-1ß, are known to be also released with a peak in the early exudative and inflammatory phases of tissue repair after MI (36). Il-1ß can induce B1R upregulation through an induction of transcription as well as a post-transcriptional mRNA stabilization (37). Thus, it is reasonable that cytokines may force kinin-dependent vasodi- lation and vascular hyperpermeability by BKreceptor induction, both important for initiating the subsequent repair phases.

The so-called inflammatory phase of wound healing, beginning $24 \mathrm{~h}$ after MI induction, is characterized by the migration of macrophages and the formation of fibroblasts and myofibroblasts. These cell types are known to express BK receptors $(21,38)$, whose activation can now promote the release of cytokines $(39,40)$. Induction of additional cytokines may extend the pro-inflammatory function of BK to contribute to inflammation and wound healing. Thus, the left ventricular increase of B1R and B2R expression $24 \mathrm{~h}$ after MI induction could result from an initiation of formation of granulation tissue for subsequent tissue repair. The B1R agonist des-Arg'-BK was found to strongly contract myofibroblasts in granulation tissue (41). Furthermore, des-Arg ${ }^{9}$-BK is thought to be involved in coronary endothelial cell proliferation (42). Both could be relevant for retraction of scar tissue and angiogenesis, respectively, and may implicate also a role of the B1R in tissue repair after induction of MI.

However, since B2R up-regulation is maintained for at least 6 days after induction of MI, an involvement of the B2R is also indicated in the following phases of tissue repair. In these late inflammatory and fibrogenic phases fibroblasts/myofibroblasts play a major role in synthesizing components of the cardiac extracellular matrix. BK has been hypothesized to be a reciprocal regulator of collagen turnover by suppressing fibroblast/myofibroblast-induced growth in the heart $(8,31,43,44)$. Studies with angiotensin-converting enzyme inhibitors and/or B2R antagonists extended the knowledge of the anti-proliferative B2R-regulated effect (45-48).

In contrast, at day 6 after MI induction the expression of the B1R had already returned to values close to those found $6 \mathrm{~h}$ post-MI. This time-dependent regulation 
curve of the B1R indicates its role in the early period of tissue injury after MI induction, which may differ from the B2R axis of the KKS. Further studies are necessary to determine whether the reduction of $\mathrm{B} 1 \mathrm{R}$ expression up to the 6th day of MI induction also indicates a termination of B1R-associated effects or whether it just belongs to a controlled fine regulation of a stable expressed receptor system.

\section{Differences in the local regulation of bradykinin receptors after MI induction}

After induction of MI, we found B2R upregulation in the infarcted LV as well as in the interventricular septum and RV, both sites remote from infarction. It is known that the RV also undergoes remodeling after induction of MI and this can be worsened by pre-treatment with the $\mathrm{B} 2 \mathrm{R}$ antagonist, icatibant, indicating that kinins also control remodeling in non-infarcted heart areas via B2R (48). However, up-regulation of the $B 2 R$ in the RV and interventricular septum may be determined by mechanisms other than those in the LV, where direct inflamma- tory processes may be involved. Future investigations will show whether humoral factors such as circulating cytokines and/or hemodynamic changes such as an increase in diastolic wall stress serve as triggers for B2R regulation at the infarction-remote sites of the infarcted heart.

In contrast, we found an induction of B1R only in the LV but not in the RV, indicating a different role in cardiac remodeling compared to the B2R.

\section{Conclusion}

We conclude that the known increase in BK levels after induction of MI is accompanied by B1R and B2R up-regulation in the early stages of cardiac wound healing, indicating the role of kinins in tissue repair and cardiac remodeling. Furthermore, we found clear differences in the expression patterns of both BK receptors in our model. Thus, the known activation of the cardiac KKS after MI differs in the profile of the B1R and B2R up-regulation, indicating a dual pathway of the KKS in the complex process of tissue injury.

\section{References}

1. Tschöpe C, Gohlke P, Zhu Y-Z, Linz W, Schölkens BA \& Unger Th (1997). Antihypertensive and cardioprotective effects after angiotensin-converting enzyme inhibition: role of kinins. J ournal of Cardiac Failure, 3: 134-148.

2. Nolly H, Carbini LA, Scicli G, Carretero OA \& Scicli AG (1994). A local kallikrein-kinin system is present in hearts. Hypertension, 23: 919-923.

3. Chao J , Swain C, Chao S, Xiong W \& Chao L (1988). Tissue distribution and kininogen expression after acute-phase inflammation. Biochimica et Biophysica Acta, 964: 329-339.

4. Nagaoka M, Yayama K, Takano M \& Okamoto H (1999). Expression of kininogen genes by rat cardiomyocytes. Immunopharmacology, 44: 81-85.
5. Minshall RD, Nakamura F, Becker RP \& Rabito SF (1995). Characterisation of bradykinin B2 receptors in adult myocardium and neonatal rat cardiomyocytes. Circulation Research, 76: 773-780.

6. Madeddu P, Parpaglia P, Demontis MP, Varoni MV, Fattaccio MC, Anania V \& Glorioso N (1995). Early blockade of bradykinin B2-receptors alters the adult cardiovascular phenotype in rats. Hypertension, 25: 453-459.

7. Emanueli $C$, Maestri R, Carradi D, Marchione R, Minasi A, Tozzi MG, Sali MB, Straino S, Capogrossi MC, Olivettti G \& Madeddu P (1999). Dilated and failing cardiomyopathy in bradykinin B2 receptor knock out mice. Circulation, 100: 23592365.

8. Walsh DA \& Fan T-P (1997). Bradykinin as a growth factor. In: Farmer St.G (Editor), The Kinin System. Academic Press, London, 301-314.

9. Marceau F, Hess JF \& Bachvarov DR (1998). The B1 receptors for kinins. Pharmacological Reviews, 50: 357-386.

10. Lamontagne $D$, Nakhostine $N$, Couture R $\&$ Nadeau R (1996). Mechanisms of kinin B1-receptor-induced hypotension in the anaesthetized dog. J ournal of Cardiovascular Pharmacology, 28: 645-650.

11. Siebeck $M$, Whalley ET, Hoffmann $H$, Weipert J \& Fritz H (1989). The hypotensive response to des-Arg ${ }^{9}$-bradykinin increases during E. coli septicemia in the pig. Advances in Experimental Medicine and Biology, 247B: 389-393.

12. Foucart S, Grondin L, Couture R \& Nadeau $R$ (1997). Modulation of noradrenaline re- 
lease by $\mathrm{B} 1$ and $\mathrm{B} 2$ kinin receptors during metabolic anoxia in the rat isolated atria. Canadian J ournal of Physiology and Pharmacology, 75: 639-645.

13. Chahine R, Adam A, Yamaguchi N, Gaspo R, Regoli D \& Nadeau R (1993). Protective effects of bradykinin on the ischemic heart: implication of the $\mathrm{B} 1$ receptor. British J oumal of Pharmacology, 108: 318322.

14. Bouchard J F, Chouinard J \& Lamontagne D (1998). Role of kinins in the endothelial protective effect of ischemic preconditioning. British J ournal of Pharmacology, 123: 413-420.

15. Regoli D \& Barabé J (1980). Pharmacology of bradykinin and related kinins. Pharmacological Reviews, 55: 866-867.

16. Hess J F, Borkowski J A, Young GS, Strader CD \& Ransom RW (1992). Cloning and pharmacological characterization of a human bradykinin (BK-2) receptor. Biochemical and Biophysical Research Communications, 184: 260-268.

17. Austin $\mathrm{KE}$, Faussner $\mathrm{A}$, Robinson $\mathrm{HE}$, Chakravarty S, Kyle DJ, Bathon JM \& Proud D (1997). Stable expression of the kinin B1 receptor in Chinese hamster ovary cells. J ournal of Biological Chemistry, 271: 11420-11425.

18. Faussner A, Bathon J M \& Proud D (1999). Comparison of the responses of $\mathrm{B} 1$ and B2 kinin receptors to agonist stimulation. Immunopharmacology, 45: 13-20.

19. Linz W, Wiemer G, Gohlke P, Unger Th \& Schölkens BA (1995). Contribution of kinins to the cardiovascular actions of angiotensin-converting enzyme inhibitors. Pharmacological Reviews, 47: 25-50.

20. Praddaude F, Tack I, Emond C, Bascands J L, Girolami J P, Tran-Van T, Regoli D \& Ader J L (1995). In vivo and in vitro homologous desensitization of rat glomerular bradykinin B2 receptors. European J ournal of Pharmacology, 294: 173-182.

21. Blaukat A, AbdAlla S, Lohse MJ \& MüllerEsterl W (1996). Ligand-induced phosphorylation/dephosphorylation of the endogenous bradykinin B2 receptor from human fibroblasts. J ournal of Biological Chemistry, 271: 32366-32374.

22. Ni A, Chao $L \&$ Chao J (1998). Transcription factor nuclear factor $\kappa B$ regulates the inducible expression of the human B1 receptor gene in inflammation. J oumal of Biological Chemistry, 273: 2784-2791.

23. Schanstra J $P$, Bataille $E$, Marin Castano ME, Barascud $Y$, Hirtz C, Pesquero J B, Pecher C, Gauthier F, Girolami JP \& Bascands J L (1998). The B1-agonist [desArg $\left.{ }^{10}\right]$-kallidin activates transcription fac- tor NF-kappaB and induces homologous upregulation of the bradykinin B1-receptor in cultured human lung fibroblasts. J ournal of Clinical Investigation, 101: 2080-2091.

24. Lochner W \& Parratt J R (1966). A comparison of the effects of locally and systematically administrated kinins on coronary blood flow and myocardial metabolism. British J ournal of Pharmacology, 26: 17-26.

25. Kimura $\mathrm{E}$, Hashimoto $\mathrm{K} \&$ Furakawa $\mathrm{H}$ (1973). Changes in bradykinin level in coronary sinus blood after the experimental occlusion of a coronary artery. American Heart J ournal, 85: 635-647.

26. Hashimoto K, Hirose M, Furukawa K, Hayakawa H \& Kimura E (1977). Changes in hemodynamic and bradykinin concentration in coronary sinus blood in experimental coronary artery occlusion. Japanese Heart J ournal, 18: 679-680.

27. Baumgarten $C R$, Linz W, Kunke $G$, Schölkens BA \& Wiemer G (1993). Ramiprilat increases bradykinin outflow from isolated rat hearts. British J ournal of Pharmacology, 108: 293-295.

28. Lamontagne $D$, Nadeau $R$ \& Adam A (1995). Effect of enalaprilat on bradykinin and des-Arg' ${ }^{9}$-bradykinin release following reperfusion of the ischemic rat heart. British J ournal of Pharmacology, 115: 476478.

29. Hashimoto $K$, Hamamoto $H$, Honda $Y$, Hirose M, Furukawa S \& Kimura E (1978). Changes in components of kinin system and hemodynamic in acute myocardial infarct. American Heart J ournal, 95: 619626.

30. Rösen $P$, Rösen $R$, Hohl C, Reinauer $H$ \& Klaus W (1984). Reduced transcoronary exchange and prostaglandin synthesis in diabetic rat heart. American J ournal of Physiology, 247: H563-H569.

31. Weber KT, Sun Y, Katwa LC \& Cleutjens J PM (1995). Connective tissue: a metabolic entity? J ournal of Molecular and Cellular Cardiology, 27: 107-120.

32. Marceau $F$, Larrivee J $-F$, Bouthillier J, Bachvarova M, Hule S \& Bachvarov DR (1999). Effect of endogenous kinins, prostanoids, and $\mathrm{NO}$ on kinin $\mathrm{B} 1$ and $\mathrm{B} 2$ receptor expression in the rabbit. American J oumal of Physiology, 277: R1568R1578.

33. Tschöpe $C$, Heringer-Walther $S$, Koch $M$, Spillmann $F$, Wendorf $M$, Hauke D, Bader M, Schultheiss H-P \& Walther T (2000). Myocardial bradykinin B2-receptor expression at different time points after induction of myocardial infarction. J ournal of
Hypertension (in press).

34. Tschöpe C, Koch M, Spillmann F, Heringer-Walther S, Mochmann $\mathrm{H}-\mathrm{Ch}$, Stauss $\mathrm{H}$, Bader $\mathrm{M}$, Unger Th, Schultheiss H-P \& Walther T (1999). Upregulation of the cardiac bradykinin B2 receptor after myocardial infarction. Immunopharmacology, 44: 111-117.

35. Tschöpe $C$, Heringer-Walther S, Koch $M$, Spillmann $F$, Wendorf $M$, Leitner $E$, Schultheiss H-P \& Walther T (2000). Upregulation of bradykinin B1-receptor expression after myocardial infarction. British J ournal of Pharmacology (in press).

36. Yue $P$, Massie BM, Simpson PC \& Long CS (1998). Cytokine expression increases in nonmyocytes from rats with postinfarction heart failure. American J ournal of Physiology, 44: $\mathrm{H} 250-\mathrm{H} 258$.

37. Zhou X, Polgar $P \&$ Taylor L (1998). Roles for interleukin-1ß, phorbol ester and a post-transcriptional regulator in the control of bradykinin B1 receptor gene expression. Biochemical J oumal, 330: 361366.

38. Faussner $A$, Heinz-Erian $P$, Klier $C \&$ Roscher AA (1991). Solubilization and characterization of B2 bradykinin receptors from cultured human fibroblasts. J ournal of Biological Chemistry, 266: 9442-9446.

39. Tiffany CW \& Burch RM (1989). Bradykinin stimulates tumor necrosis factor and interleukin $1 ß$ release from macrophages. FEBS Letters, 247: 189-192.

40. Pan ZK, Zuraw BL, Lung C-C, Prossnitz ER, Browning DD \& Ye RD (1996). Bradykinin stimulates NF-kB activation and interleukin $1 ß$ gene expression in cultured human fibroblasts. J ournal of Clinical Investigation, 98: 2042-2049.

41. Appleton I, Rosenblatt L \& Willoughby DA (1994). Synergistic effect of recombinant human epidermal growth factor and desArg'-bradykinin, on rat croton oil-induced granulation tissue contraction. British J ournal of Pharmacology, 111: 290P (Abstract).

42. Morbidelli L, Parenti A, Giovannelli L, Granger HJ , Ledda F \& Ziche M (1998). B1 receptor involvement in the effect of bradykinin on venular endothelial cell proliferation and potentiation of FGF-2 effects. British J oumal of Pharmacology, 124: 1286-1292.

43. Sun Y, Diaz-Arias AA \& Weber KT (1994). Angiotensin-converting enzyme, bradykinin and angiotensin II receptor binding in rat skin, tendon and heart valves: an in vitro quantitative autoradiographic study. J ournal of Laboratory and Clinical Medi- 
cine, 123: 372-377.

44. Kim NN, Villegas S, Summerour SR \& Villarreal FJ (1999). Regulation of cardiac fibroblast extracellular matrix production by bradykinin and nitric oxide. J ournal of Molecular and Cellular Cardiology, 31: 457-466.

45. Martorana PA, Kettenbach B, Breipohl G, Linz W \& Schölkens BA (1990). Reduction of infarct size by local angiotensin-converting enzyme inhibition is abolished by a bradykinin antagonist. European J ournal of Pharmacology, 182: 395-396.

46. Stauss HM, Zhu YC, Redlich T, Adamiak D, Mott A, Kregel K \& Unger T (1994). ACE inhibitors in infarct induced heart failure: bradykinin versus angiotensin II. J ournal of Cardiovascular Risk, 1: 255-262.

47. McDonald KM, Carlyle PF, Mathews J, Hauer K, Elbers T, Hunter D \& Cohn J N (1990). Early ventricular remodelling after myocardial damage and its attenuation by converting enzyme inhibition. Transactions of the Association of American Physicians, 103: 229-235.

48. Hu K, Goudron P, Anders H-J , Weidemann $F$, Turschner O, Nahrendorf M \& Ertl G (1998). Chronic effects of early started angiotensin converting enzyme inhibition and angiotensin AT1-receptor subtype blockade in rats with myocardial infarction: role of bradykinin. Cardiovascular Research, 39: 401-412. 